\title{
Article \\ The Short-Term Outcomes of Multiwave Locked System (MLS) Laser Therapy versus a Combination of Transcutaneous Nerve Stimulation and Ultrasound Treatment for Subacromial Pain Syndrome
}

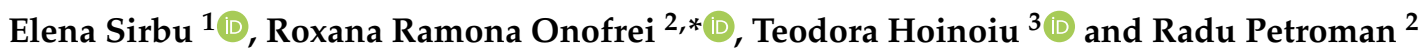 \\ 1 Department of Physical Therapy and Special Motility, West University of Timişoara, \\ 300223 Timisoara, Romania; elena_sarbu@yahoo.co.uk \\ 2 Department of Rehabilitation, Physical Medicine and Rheumatology, Research Center for Assessment of \\ Human Motion, Functionality and Disability, "Victor Babes" University of Medicine and Pharmacy Timisoara, \\ 300041 Timisoara, Romania; petroman.radu@umft.ro \\ 3 Department of Clinical Practice Skills, "Victor Babes" University of Medicine and Pharmacy Timisoara, \\ 300041 Timisoara, Romania; tstoichitoiu@umft.ro \\ * Correspondence: onofrei.roxana@umft.ro
}

Citation: Sirbu, E.; Onofrei, R.R.; Hoinoiu, T.; Petroman, R. The Short-Term Outcomes of Multiwave Locked System (MLS) Laser Therapy versus a Combination of Transcutaneous Nerve Stimulation and Ultrasound Treatment for Subacromial Pain Syndrome. Appl. Sci. 2021, 11, 2273. https://doi.org/ 10.3390/app11052273

Received: 21 January 2021

Accepted: 3 March 2021

Published: 4 March 2021

Publisher's Note: MDPI stays neutral with regard to jurisdictional claims in published maps and institutional affiliations.

Copyright: () 2021 by the authors. Licensee MDPI, Basel, Switzerland. This article is an open access article distributed under the terms and conditions of the Creative Commons Attribution (CC BY) license (https:// creativecommons.org/licenses/by/ $4.0 /)$.
Abstract: The purpose of this study was to compare the short-term outcomes of the Multiwave Locked System (MLS) laser therapy versus the combined Transcutaneous nerve stimulation (TENS) and ultrasound therapy in the treatment of the subacromial pain syndrome (SAPS). Forty-seven patients with SAPS were included in the study. Two different rehabilitation protocols were tested: Group 1 ( $n=22)-$ MLS laser therapy and physical exercises and Group $2(n=25)-T E N S$, ultrasound and physical exercises. The analyzed outcomes were levels of pain, functionality and disability, assessed with visual analog scale (VAS), Constant Shoulder Score (CSS) and the Shoulder Pain and Disability Index (SPADI). The post-treatment evaluations showed significantly better scores in Group 1 patients for VAS score $(p=0.03)$ and SPADI $(p=0.04)$. Significant improvement was seen in both groups for all scores. Both treatment regimens showed to be efficient in the treatment of SAPS, improving functionality and reducing pain and disability in the short term. Multiwave Locked System laser therapy in conjunction with physical exercise therapy exercises may have advantages over TENS, ultrasound and physical exercise therapy in the treatment of subacromial pain syndrome. Future studies assessing both short- and long-term outcomes in patients with SAPS treated with different electrotherapy procedures added to the physical therapy are needed.

Keywords: subacromial pain syndrome; multiwave locked system; laser therapy

\section{Introduction}

Subacromial pain syndrome (SAPS), also known as subacromial impingement syndrome, is the most common cause of shoulder pain, with a prevalence of $44-65 \%$ among all shoulder pains [1,2]. SAPS refers to the structural changes suffered by the rotator cuff, as a result of its permanent conflict with the anterior edge and inferior surface of the anterior third of the acromion, coracohumeral ligament and, occasionally, with the acromioclavicular joint, when anterior abduction and/or extension movements of the shoulder are performed. The above-mentioned impingement may be produced by compression of the subacromial structures against the coracoacromial arch. The anterior type of the acromion, the coracoacromial ligament and the coracoid process are also implicated in this "impingement". Pain and functional limitation of the shoulder are the consequence of compression or altered dynamics, finally leading to the damage of the periarticular structures [3].

The factors favoring this syndrome may be intrinsic (tendinosis, repetitive microtrauma, shoulder overload, hypotonia of the rotator cuff muscles) or extrinsic (shape, 
thickness and angulation variations of the acromion, coracohumeral distance, acromioclavicular arthrosis, hyperostosis at the greater tuberosity, vascular factors) [3]. Actually, SAPS refers to a wide range of pathologies which include rotator cuff tears, calcific tendinitis, biceps tendinopathy, rotator cuff tendinosis and subacromial bursitis [4]. The incidence of shoulder impingement rises with age, with a peak incidence occurring in the sixth decade of life [5]. It is also common in repetitive overhead sports or in several jobs that require a prolonged overhead position of the arm [3].

From the clinical point of view, it is characterized by chronic pain in the shoulder, with episodes of exacerbation, due to the compression of the structures located in the bony passageway created between the humeral head and acromion, and the ligament connecting it to the coracoid process and coracoid muscles (coracoacromial arch).

In fact, the clinical picture varies from a simple supraspinatus tendonitis, in which patients complain of pain when performing an active abduction movement of the shoulder, without limitation of its mobility, to a calcific tendonitis with pain and functional impairment of the upper limb, active movement being impossible. In the frozen shoulder stage, pain disappears completely, but the mobility of the scapulohumeral joint is completely or almost completely abolished (blocked shoulder).

The main goals of treatment in SAPS are to reduce pain, improve shoulder motion, shoulder function and quality of life. Thus, the treatment strategy may vary according to the disease stage, the characteristics of the patient and the clinical experience of the therapists. The conservative methods include exercise programs, medication, manual therapy techniques and a variety of electrotherapy procedures [6].

Previous studies have reported the effectiveness of various electrotherapy procedures including pulsed electromagnetic field therapy $[7,8]$, transcutaneous nerve stimulation (TENS) [6,9], ultrasound (US) [10], low-level laser therapy (LLLT) [11] and extracorporeal shockwave therapy [12].

Laser is a pain-free and non-invasive treatment modality. It is used in many acute and chronic painful conditions. Multiwave Locked System laser therapy utilizes the synchronized emission of an $808 \mathrm{~nm}$ continuous laser and a $905 \mathrm{~nm}$ pulsed laser. It is postulated that Multiwave Locked System (MLS) enables greater penetration and therapeutic benefit than single-wavelength low-level laser therapy (LLLT) [13].

There are many studies in the literature on the use of various electrotherapy methods compared to each other or to a placebo for the conservative treatment of SAPS. To our knowledge, there are no studies comparing the impact of MLS laser therapy versus combination of transcutaneous nerve stimulation and ultrasound treatment in patients with SAPS. Therefore, the purpose of this study was to compare the short-term outcomes of the Multiwave Locked System laser therapy to the combined TENS and ultrasound therapy in the treatment of the subacromial pain syndrome. There are other possible therapies for the treatment of SAPS such as low-level laser therapy or electromagnetic field therapy $[7,8,11]$ and, in future studies, we will look into the relative merits of MLS laser therapy versus these alternatives.

\section{Materials and Methods}

Patients with long-lasting shoulder pain (at least 3 months), already diagnosed by a rheumatologist with SAPS, treated with physical therapy in an outpatient rehabilitation clinic and who were followed-up 15 days after the completion of physical therapy program were included in this study.

We excluded patients with systemic inflammatory rheumatic diseases, decompensated heart failure, neurologic deficits, spinal disorders, history of shoulder or neck surgery, referred pain. Patients who received analgesics or steroid injections for their shoulder pain were also excluded.

Written informed consent was obtained from all participants that accomplished inclusion criteria and agreed to participate in the study [14]. This study was conducted in accordance with the Declaration of Helsinki and was approved by the Ethics Committee of 
the University (approval number 32035/0-1/22.07.2020). The study was registered as a non-randomized trial, with no IRCT20200422047172N1.

Data were collected from the patients' records, including socio-demographic data (age, gender, height, weight and occupation), the affected shoulder (left or right), diagnosis, rehabilitation treatment and outcome assessments.

Based on the type of the electrotherapy procedure prescribed in addition to the rehabilitation exercises, the patients included in the study were divided into two groups. The patients in Group $1(n=22)$ had a total of 10 sessions of MLS laser therapy associated with physical therapy exercises. The duration of laser treatment was five minutes for each session. The MLS laser therapy was applied using a Mphi system (ASA Srl, Arcugnano, Italy) on the anterior and posterior part of the shoulder (Figure 1), with a laser pulse repetition frequency of $700 \mathrm{~Hz}$, a dose of $2.8 \mathrm{Joule} / \mathrm{cm}^{2}$, an intensity of $50 \%$, per $5 \mathrm{~min}$. The second group $(n=25)$ received ten US therapy sessions for the affected shoulder, as well as TENS (20 min) (Figure 2), and physical therapy exercises. Continuous ultrasound was applied using circular movements at an intensity of $1 \mathrm{~W} / \mathrm{cm}^{2}$, and $1 \mathrm{MHz}$, for $3 \mathrm{~min}$. In addition, TENS was applied using a frequency of $90 \mathrm{~Hz}$, symmetric biphasic, for $20 \mathrm{~min}$. All classical electrotherapy applications were performed using the Chattanooga Intelect Neo combined device.
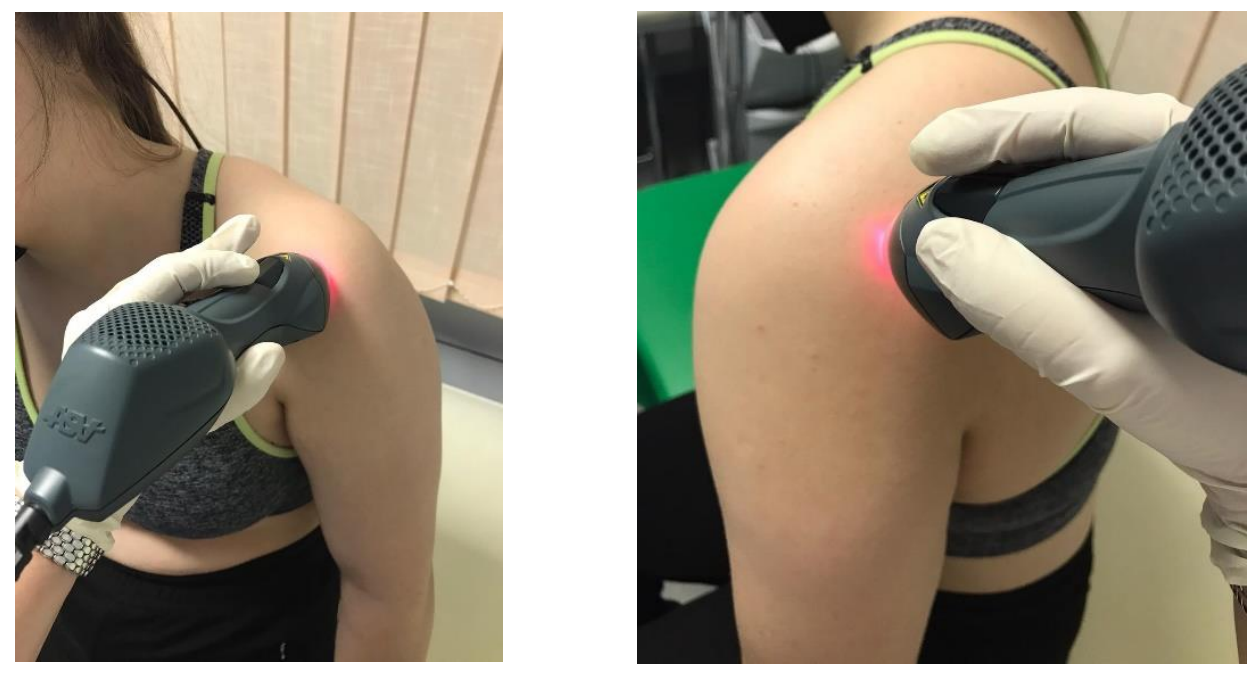

Figure 1. Multiwave Locked System (MLS) application.

Initially, all patients performed Codman exercises, passive range of motion exercises, glide mobilization techniques and stretching exercises. Further, as the pain decreased and the mobility of the affected shoulder increased, active range of motion exercises, isometric and resistive exercises were added to the therapeutic program. The above-mentioned exercises have been performed once a day with 10 repetitions and applied five times a week, for three weeks.

The patients were evaluated before treatment and 15 days after the end of treatment. Pain was evaluated using a VAS (visual analog scale), functional activity was evaluated using the Constant Shoulder Score (CSS) and the Shoulder Pain and Disability Index (SPADI).

In VAS assessment, the degree of pain at rest and during activity was evaluated on 10-cm scale, with 0 indicated "no pain" and 10 indicated "worst pain".

SPADI is a self-administered questionnaire with two subscales-pain and disability. Each question quantifies the pain felt and the degree of disability perceived at a certain movement/in carrying out a certain activity, through a numerical representation between 0 and 10, similar to completing the VAS scale. The final score is calculated, being subsequently divided by the number of questions and the final percentage result (\%) represents the existing level of pain and functional disability. The higher the score, the greater the pain and functional impairment $[15,16]$. Recently, several studies reported that the reliability 
coefficients of SPADI is good with an intraclass correlation coefficient of $\geq 0.89$. The SPADI demonstrated a good validity and a significant correlation with other shoulder questionnaires $[17,18]$.

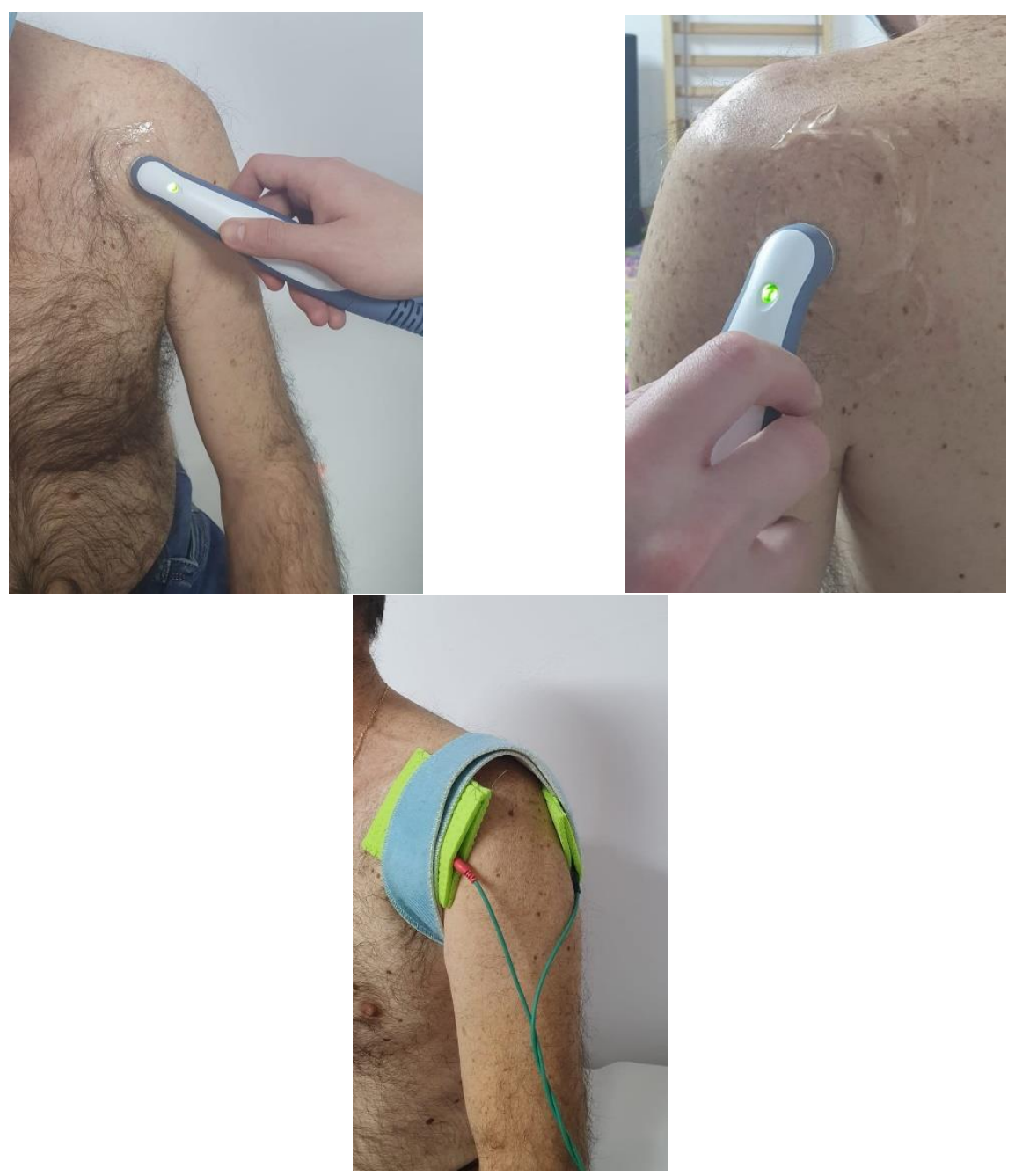

Figure 2. Ultrasound and Transcutaneous nerve stimulation (TENS) application.

Constant-Murley Shoulder Score (CSS) includes four subscales: pain (15 points), activities of daily living ( 20 points), strength ( 25 points) and range of motion ( 40 points). The total possible score was 100 points: $90-100$ points were classed as excellent, $80-89$ points as good, $70-79$ points as moderate and $<70$ points as poor. It has been reported that the intraclass correlation coefficient of CSS was $0.80-0.96$ and the reliability could be improved by a better standardization of the assessment procedure $[19,20]$. Moreover, a sensitivity of $91 \%$ and a specificity of $79 \%$ was reported for the CMS score [21].

\section{Statistical Analysis}

Statistical analysis was performed with GraphPad Prism 9 software version 9.0.0 (GraphPad Software, San Diego, CA, USA). Data were tested for normality with ShapiroWilk test. Between-group comparisons were analyzed with unpaired t-tests for normal distributed data and with Mann-Whitney for non-normal distributed data. The treatment effectiveness was analyzed with paired t-tests and Wilcoxon rank sum tests, respectively. Chi-square tests were performed to compare categorical data. Statistical significance was set at $p<0.05$. 


\section{Results}

Forty-seven patients ( $58.60 \pm 10.18$ years; $46.81 \%$ males) with SAPS were included in the study.

In Group 1, there were 22 patients (mean age- $58.73 \pm 9.47$ years; $40.91 \%$ males; $36.36 \%$ retired) and in Group 2, 25 patients (mean age- $58.48 \pm 10.96$ years; $52 \%$ males; $48 \%$ retired). No age, sex or symptom duration differences were observed between groups $(p>0.05)$. Patients' characteristics are presented in Table 1.

Table 1. Patients' characteristics.

\begin{tabular}{cccc}
\hline & Group 1 $(\boldsymbol{n = 2 2 )}$ & Group 2 $(\boldsymbol{n = 2 5 )}$ & $p$ \\
\hline Age, years (mean \pm SD) & $58.73 \pm 9.47$ & $58.48 \pm 10.96$ & 0.93 \\
Sex & & & \\
Female, $n(\%)$ & $13(59.09)$ & $12(48)$ & 0.57 \\
Male, $n(\%)$ & $9(40.91)$ & $13(52)$ & \\
Occupation & & & \\
Active, $n(\%)$ & $14(63.64)$ & $13(52)$ & 0.55 \\
Retired, $n(\%)$ & $8(36.36)$ & $12(48)$ & \\
Affected shoulder & & & \\
Right, $n(\%)$ & $11(50)$ & $16(64)$ & 0.38 \\
Left, $n(\%)$ & $11(50)$ & $9(36)$ & \\
Pathology & $15(68.18)$ & $18(72)$ & 0.99 \\
Calcified tendinitis, $n(\%)$ & $7(31.82)$ & $7(28)$ & 0.59 \\
Adhesive capsulitis, $n(\%)$ & $137.7 \pm 23.37$ & $134.2 \pm 20.17$ & 0.59 \\
\hline Symptom duration, days (mean \pm SD) & &
\end{tabular}

There were no differences at the initial evaluation between groups on all assessments. The post treatment evaluations showed significantly better scores in Group 1 patients for VAS score $(p=0.03)$ and SPADI $(p=0.04)$. Significant improvement was seen in both groups for all scores (Table 2). The improvement seen in all patients' for VAS score (postvs. pre-treatment) was greater than the minimally clinically important difference (MCID) reported for VAS pain score in patients with rotator cuff disease (greater than 1.4 [22]). All patients had an improvement greater than the reported MCID for SPADI (MCID between 8 and 13 [18]). A change greater than the reported MCID for the CSS score (MCID of 19 in patients with intact rotator cuff [21]) was reported in $90.9 \%$ of patients in Group 1 and only in $84 \%$ patients in Group 2.

Table 2. Patients' assessments before and after treatments.

\begin{tabular}{|c|c|c|c|c|c|c|}
\hline & \multicolumn{2}{|c|}{ Group $1(n=22)$} & \multicolumn{2}{|c|}{ Group $2(n=25)$} & \multirow[t]{2}{*}{$p^{* *}$} & \multirow[t]{2}{*}{$95 \% \mathrm{CI}$} \\
\hline VAS (median [IQR]) & & $p^{*}$ & & $p^{*}$ & & \\
\hline Baseline & 8 [7-8.25] & & 8 [8-9] & & 0.16 & $0-1$ \\
\hline Follow-up & $3[2-4]$ & $<0.0001$ & $4[3-6]$ & $<0.0001$ & 0.03 & $0-2$ \\
\hline Change & $5[3-6]$ & & $4[3-7]$ & & 0.11 & $0-2$ \\
\hline \multicolumn{7}{|l|}{ CSS (mean \pm SD) } \\
\hline Baseline & $26.27 \pm 11.7$ & ( & $22.56 \pm 9.86$ & & 0.24 & $-2.62-10.05$ \\
\hline Follow-up & $63.09 \pm 18.14$ & $<0.0001$ & $54.04 \pm 17.64$ & $<0.0001$ & 0.09 & $-1.47-19.58$ \\
\hline Change & $36.82 \pm 16.58$ & & $31.08 \pm 11.4$ & & 0.16 & $-2.53-14.02$ \\
\hline \multicolumn{7}{|l|}{ SPADI (mean \pm SD) } \\
\hline Baseline & $67.86 \pm 14.04$ & & $66.89 \pm 12.5$ & & 0.8 & $-8.76-6.82$ \\
\hline Follow-up & $22.9 \pm 16.76$ & $<0.0001$ & $33.34 \pm 17.08$ & $<0.0001$ & 0.04 & $0.47-20.42$ \\
\hline Change & $44.96 \pm 16.5$ & & $33.54 \pm 9.42$ & & 0.004 & $3.64-19.2$ \\
\hline
\end{tabular}

${ }^{*} p$ related to before-after treatment comparison; ${ }^{* *} p$ related to group 1 vs. Group 2 comparison; VAS-visual analog scale for pain; CSS-Constant-Murley shoulder score; IQR-interquartile range; $95 \%$ CI—95\% confidence interval.

The changes in SPADI scores between follow-up and initial assessments were significantly greater in Group 1 compared to Group $2(p=0.004)$. 


\section{Discussion}

The present study compared the short-term outcomes of two rehabilitation treatment regimens (the Multiwave Locked System laser therapy versus the combined TENS and ultrasound therapy) in the treatment of the subacromial pain syndrome. Both treatment regimens showed an improvement in analyzed outcomes (pain, functionality and disability). In addition, MLS therapy with physical therapy exercises may have clinical advantages over the combination of TENS, US and exercises in the treatment of SAPS, with a significant improvement in pain and functional disability.

SAPS is a common cause of shoulder pain and disability. Management of SAPS includes several non-surgical and surgical treatment procedures. The conservative procedures' objectives are to reduce pain, inflammation, to improve range of motion and to stimulate the tendon's healing [7]. Studies have investigated different treatment strategies, with exercises being the most important component [23,24].

To our knowledge, there are no studies investigating the effects of MLS in the treatment of SAPS. Vignali et al. [25] reported an improvement of pain and function in patients with different tendinopathies treated with MLS. Their patients with shoulder tendinopathies had positive, but statistically non-significant results, due to the small sample size. Our results showed a significant decrease in pain as assessed by VAS and also a significant improvement in functionality, as assessed by SPADI. The improvement in SPADI scores was significantly greater in patients treated with MLS laser therapy. In our study, the improvements seen in pain, functionality and disability after both treatment regimens have been proved to be not only statistically significant, but also clinically relevant, the changes in scores being greater than the reported MCIDs. Since the 95\% confidence interval for the differences at follow-up and for the changes overlaps the MCID for VAS and SPADI, the observed differences could be possibly clinically significant, but no conclusion could be drawn until more data are obtained [26-28].

The effects of high-intensity laser therapy in subacromial impingement syndrome have been studied by Karaca et al. [29]. The author reported the short-term effectiveness of high-intensity laser therapy, decreasing pain and improving disability. The change seen in SPADI score in the above-mentioned study is in accordance with our results, with a decrease in pain and disability. Santamato et al. compared the short-term effects of high-intensity laser therapy versus ultrasound in subacromial impingement syndrome patients and found a greater reduction in pain and improvement in articular movement functionality in the affected shoulder in patients treated with high-intensity laser [30].

The analgesic and anti-inflammatory effectiveness of MLS therapy has been observed in different pathologies like chronic neck pain, knee osteoarthritis, Raynaud phenomenon, bursitis, carpal tunnel syndrome, and myofascial pain [13,31-36]. In their study, Iacopetti et al. [37] observed an anti-inflammatory effect and also an improved collagen fiber organization in an experimentally induced tendinopathy in sheep after the use of MLS in doses of $2.5 \mathrm{~J} / \mathrm{cm}^{2}$. Moreover, a study conducted in Poland on 30 patients with rheumatoid arthritis showed the effectiveness of MLS laser therapy in reduction of pain and swelling of joints but also an improvement of hand function and quality of life [38]. The analgesic and anti-inflammatory effects of MLS could be explained by the photothermal and photochemical effects induced in the deep tissues, increasing the collagen production and improving blood flow, cell metabolism and vascular permeability [39]. The therapeutic effects of US are mainly due to its thermal properties, improving circulation and elasticity of collagenous tissues, decreasing muscle spasms and destroying scar tissue [40].

Our study has some limitations, and the relatively small number of patients in both groups is one of these limitations. We did not include in the analysis a control group of patients with SAPS treated only with physical exercises. The reason was that the patients addressed to the rehabilitation had significant long-lasting pain, and exercise alone was considered insufficient to ameliorate pain. The study included only one follow-up, not providing information about long-term function. Future studies assessing both short- and 
long-term outcomes in patients with SAPS treated with different electrotherapy procedures added to the physical therapy are needed.

\section{Conclusions}

Both treatment regimens showed to be efficient in the treatment of SAPS, improving pain, functionality and reducing disability on short-term. Multiwave Locked System laser therapy in conjunction with physical exercise therapy exercises may have advantages over TENS, ultrasound and physical exercise therapy in the treatment of subacromial pain syndrome.

Author Contributions: Conceptualization, E.S. and R.P.; methodology, E.S.; formal analysis, R.R.O.; investigation, E.S. and R.P.; data curation, R.R.O. and R.P.; writing—original draft preparation, E.S., R.R.O., T.H. and R.P.; writing—review and editing, E.S., R.R.O., T.H. and R.P.; supervision, E.S. All authors have read and agreed to the published version of the manuscript.

Funding: This research received no external funding.

Institutional Review Board Statement: The study was conducted according to the guidelines of the Declaration of Helsinki, and approved by the Institutional Ethics Committee of the West University of Timişoara (32035/0-1/22.07.2020).

Informed Consent Statement: Informed consent was obtained from all subjects involved in the study.

Data Availability Statement: Not applicable.

Acknowledgments: The authors thank Avram Raluca.

Conflicts of Interest: The authors declare no conflict of interest.

\section{References}

1. Huang, H.-Y.; Lin, J.-J.; Guo, Y.L.; Wang, W.T.-J.; Chen, Y.-J. EMG biofeedback effectiveness to alter muscle activity pattern and scapular kinematics in subjects with and without shoulder impingement. J. Electromyogr. Kinesiol. 2013, 23, 267-274. [CrossRef] [PubMed]

2. Chester, R.; Smith, T.O.; Hooper, L.; Dixon, J. The impact of subacromial impingement syndrome on muscle activity patterns of the shoulder complex: A systematic review of electromyographic studies. BMC Musculoskelet. Disord. 2010, 11, 45. [CrossRef]

3. Fodor, D. Ecografie Clinica Musculoscheletala; Editura Medicala: București, Romania, 2009.

4. Koester, M.C.; George, M.S.; Kuhn, J.E. Shoulder impingement syndrome. Am. J. Med. 2005, 118, 452-455. [CrossRef] [PubMed]

5. Garving, C.; Jakob, S.; Bauer, I.; Nadjar, R.; Brunner, U.H. Impingement Syndrome of the Shoulder. Dtsch Arztebl Int. 2017, 114, 765-776. [CrossRef]

6. Gunay Ucurum, S.; Kaya, D.O.; Kayali, Y.; Askin, A.; Tekindal, M.A. Comparison of different electrotherapy methods and exercise therapy in shoulder impingement syndrome: A prospective randomized controlled trial. Acta Orthop. Traumatol. Turc. 2018, 52, 249-255. [CrossRef] [PubMed]

7. Aktas, I.; Akgun, K.; Cakmak, B. Therapeutic effect of pulsed electromagnetic field in conservative treatment of subacromial impingement syndrome. Clin. Rheumatol. 2007, 26, 1234-1239. [CrossRef] [PubMed]

8. Galace de Freitas, D.; Marcondes, F.B.; Monteiro, R.L.; Rosa, S.G.; Maria de Moraes Barros Fucs, P.; Fukuda, T.Y. Pulsed Electromagnetic Field and Exercises in Patients with Shoulder Impingement Syndrome: A Randomized, Double-Blind, PlaceboControlled Clinical Trial. Arch. Phys. Med. Rehabil. 2014, 95, 345-352. [CrossRef] [PubMed]

9. Page, M.J.; Green, S.; Mrocki, M.A.; Surace, S.J.; Deitch, J.; Mcbain, B.; Lyttle, N.; Buchbinder, R. Electrotherapy modalities for rotator cuff disease. Cochrane Database Syst. Rev. 2016, 6, CD012225. [CrossRef] [PubMed]

10. Yildirim, M.A.; Ones, K.; Celik, E.C. Comparision of ultrasound therapy of various durations in the treatment of subacromial impingement syndrome. J. Phys. Ther. Sci. 2013, 25, 1151-1154. [CrossRef] [PubMed]

11. Yavuz, F.; Duman, I.; Taskaynatan, M.A.; Tan, A.K. Low-level laser therapy versus ultrasound therapy in the treatment of subacromial impingement syndrome: A randomized clinical trial. J. Back Musculoskelet. Rehabil. 2014, 27, 315-320. [CrossRef]

12. Engebretsen, K.; Grotle, M.; Bautz-Holter, E.; Sandvik, L.; Juel, N.G.; Ekeberg, O.M.; Brox, J.I. Radial extracorporeal shockwave treatment compared with supervised exercises in patients with subacromial pain syndrome: Single blind randomised study. BMJ 2009, 339, b3360. [CrossRef]

13. Alayat, M.S.; Elsoudany, A.M.; Ali, M.E. Efficacy of Multiwave Locked System Laser on Pain and Function in Patients with Chronic Neck Pain: A Randomized Placebo-Controlled Trial. Photomed. Laser Surg. 2017, 35, 450-455. [CrossRef]

14. Roman, N.; Tirziman, E.; Sorea, D.; Miclaus, R.; Repanovici, A.; Amaricai, E.; Rogozea, L. Ethical dilemmas in the interdisciplinary approach to informed consent to patients in physiotherapy services in Romania. Rev. Cercet. Interv. Soc. 2018, 63, $290-303$. 
15. Ekeberg, O.M.; Bautz-Holter, E.; Tveitå, E.K.; Keller, A.; Juel, N.G.; Brox, J.I. Agreement, reliability and validity in 3 shoulder questionnaires in patients with rotator cuff disease. BMC Musculoskelet. Disord. 2008, 9, 68. [CrossRef] [PubMed]

16. MacDermid, J.C.; Solomon, P.; Prkachin, K. The Shoulder Pain and Disability Index demonstrates factor, construct and longitudinal validity. BMC Musculoskelet. Disord. 2006, 7, 12. [CrossRef] [PubMed]

17. Hill, C.L.; Gill, T.K.; Shanahan, E.M.; Taylor, A.W. Prevalence and correlates of shoulder pain and stiffness in a population-based study: The North West Adelaide Health Study. Int. J. Rheum. Dis. 2010, 13, 215-222. [CrossRef]

18. Roy, J.-S.; MacDermid, J.C.; Woodhouse, L.J. Measuring shoulder function: A systematic review of four questionnaires. Arthritis Care Res. 2009, 61, 623-632. [CrossRef] [PubMed]

19. Roy, J.-S.; MacDermid, J.C.; Woodhouse, L.J. A systematic review of the psychometric properties of the Constant-Murley score. J. Shoulder Elb. Surg. 2010, 19, 157-164. [CrossRef]

20. Rocourt, M.H.H.; Radlinger, L.; Kalberer, F.; Sanavi, S.; Schmid, N.S.; Leunig, M.; Hertel, R. Evaluation of intratester and intertester reliability of the Constant-Murley shoulder assessment. J. Shoulder Elb. Surg. 2008, 17, 364-369. [CrossRef] [PubMed]

21. Holmgren, T.; Öberg, B.; Adolfsson, L.; Björnsson Hallgren, H.; Johansson, K. Minimal important changes in the Constant-Murley score in patients with subacromial pain. J. Shoulder Elb. Surg. 2014, 23, 1083-1090. [CrossRef]

22. Tashjian, R.Z.; Deloach, J.; Porucznik, C.A.; Powell, A.P. Minimal clinically important differences (MCID) and patient acceptable symptomatic state (PASS) visual analog scales (VAS) measuring pain in patients treated for rotator cuff disease. J. Shoulder Elb. Surg. 2009, 18, 927-932. [CrossRef]

23. Gebremariam, L.; Hay, E.M.; van der Sande, R.; Rinkel, W.D.; Koes, B.W.; Huisstede, B.M.A. Subacromial impingement syndrome-Effectiveness of physiotherapy and manual therapy. Br. J. Sports Med. 2014, 48, 1202 LP-1208 LP. [CrossRef]

24. Calis, H.T.; Berberoglu, N.; Calis, M. Are ultrasound, laser and exercise superior to each other in the treatment of subacromial impingement syndrome? A randomized clinical trial. Eur. J. Phys. Rehabil. Med. 2011, 47, 375-380. [PubMed]

25. Vignali, L.; Caruso, G.; Gervasi, S.; Cialdai, F. MLS Laser Therapy in the treatment of patients affected by tendinopathies. Energy Health 2017, 16, 10-15.

26. Katz, N.P.; Paillard, F.C.; Ekman, E. Determining the clinical importance of treatment benefits for interventions for painful orthopedic conditions. J. Orthop. Surg. Res. 2015, 10, 24. [CrossRef]

27. Harris, J.D.; Brand, J.C.; Cote, M.P.; Faucett, S.C.; Dhawan, A. Research Pearls: The Significance of Statistics and Perils of Pooling. Part 1: Clinical Versus Statistical Significance. Arthroscopy 2017, 33, 1102-1112. [CrossRef]

28. Chan, L.S. Minimal clinically important difference (MCID)_Adding meaning to statistical inference. Am. J. Public Health 2013, 103, e24-e25. [CrossRef] [PubMed]

29. Karaca, B. Effectiveness of High-Intensity Laser Therapy in Subacromial Impingement Syndrome. Photomed. Laser Surg. 2016, 34, 223-228. [CrossRef] [PubMed]

30. Santamato, A.; Solfrizzi, V.; Panza, F.; Tondi, G.; Frisardi, V.; Leggin, B.G.; Ranieri, M.; Fiore, P. Short-term Effects of High-Intensity Laser Therapy Versus Ultrasound Therapy in the Treatment of People With Subacromial Impingement Syndrome: A Randomized Clinical Trial. Phys. Ther. 2009, 89, 643-652. [CrossRef]

31. Gworys, K.; Gasztych, J.; Puzder, A.; Gworys, P.; Kujawa, J. Influence of various laser therapy methods on knee joint pain and function in patients with knee osteoarthritis. Ortop. Traumatol. Rehabil. 2012, 14, 269-277. [CrossRef]

32. Dakowicz, A.; Kuryliszyn-Moskal, A.; Białowieżec, M.; Gbur, A. Assessment of the Effectiveness of MLS Laser Therapy in the Treatment of Patients with Knee Osteoarthritis. Polish J. Appl. Sci. 2017, 1, 124-129.

33. Kuryliszyn-Moskal, A.; Kita, J.; Dakowicz, A.; Chwieśko-Minarowska, S.; Moskal, D.; Kosztyła-Hojna, B.; Jabłońska, E.; Klimiuk, P.A. The influence of Multiwave Locked System (MLS) laser therapy on clinical features, microcirculatory abnormalities and selected modulators of angiogenesis in patients with Raynaud's phenomenon. Clin. Rheumatol. 2015, 34, 489-496. [CrossRef] [PubMed]

34. Momanu, A. Comparison of analgesic and anti-inflammatory effects of the classical low laser therapy and multiwave locked system in inflammations of serous bursae. Med. Sport. J. Rom. Sport. Med. Soc. 2013, 9, 2234-2240.

35. Pattapong, N.; Wongwanna, K.; Iamlaoor, P.; Jaion, P. Effectiveness of Multiwave Locked System Laser therapy in treatment of Carpal Tunnel Syndrome Patients. Naresuan Univ. J. Sci. Technol. 2016, 24, $24-35$.

36. Manfredini, D.; Favero, L.; Cocilovo, F.; Monici, M.; Guarda-Nardini, L. A comparison trial between three treatment modalities for the management of myofascial pain of jaw muscles: A preliminary study. Cranio 2018, 36, 327-331. [CrossRef]

37. Iacopetti, I.; Perazzi, A.; Maniero, V.; Martinello, T.; Patruno, M.; Glazar, M.; Busetto, R. Effect of MLS $\left({ }^{\circledR}\right)$ laser therapy with different dose regimes for the treatment of experimentally induced tendinopathy in sheep: Pilot study. Photomed. Laser Surg. 2015, 33, 154-163. [CrossRef]

38. Chwiesko-Minarowska, S.; Kuryliszyn-Moskal, A.; Pijanowska, M.; Jablonska, M. The comparison of multi-waved locked system laser and low-frequency magnetic field therapy on hand function and quality of life in patients with rheumatoid arthritis-preliminary study. Acta Balneol. 2014, 56, 181-184.

39. Wyszyńska, J.; Bal-Bocheńska, M. Efficacy of High-Intensity Laser Therapy in Treating Knee Osteoarthritis: A First Systematic Review. Photomed. Laser Surg. 2018, 36, 343-353. [CrossRef]

40. Celik, D.; Atalar, A.C.; Sahinkaya, S.; Demirhan, M. The value of intermittent ultrasound treatment in subacromial impingement syndrome. Acta Orthop. Traumatol. Turc. 2009, 43, 243-247. [CrossRef] 